\title{
Spine Trauma
}

\author{
Connie Y. Chang and Mini N. Pathria
}

\section{Learning Objectives}

- To describe common and important traumatic lesions of the spine, emphasizing different injuries that take place in different spinal segments.

- To illustrate the typical imaging appearance of spinal injuries on radiographs, computed tomography (CT), and magnetic resonance imaging (MRI).

- To introduce radiologists to the most widely used scoring systems used by orthopedic surgeons and neurosurgeons for classifying spinal trauma and selecting management.

Spine trauma is a common indication for diagnostic imaging, and the use of advanced imaging for assessment of spinal injury has become routine at major trauma centers. Injuries of the spine are best understood by considering it as five distinct anatomic regions, each with its own unique anatomy and patterns of injury. These regions consist of the cervicothoracic, low cervical, thoracic, thoracolumbar, and low lumbar segments of the spine, with the majority of injuries occurring in the low cervical and thoracolumbar areas.

\subsection{Craniocervical Junction (CCJ)}

The craniocervical junction includes three bones (occipital base, C1, and C2), two joints (atlantooccipital and atlantoaxial), and several extrinsic and intrinsic ligaments, allowing for the delicate balance of flexibility while protecting the

C. Y. Chang $(\square)$

Massachusetts General Hospital, Boston, MA, USA

e-mail: cychang@mgh.harvard.edu

M. N. Pathria

UCSD Health System, San Diego, CA, USA

e-mail: mpathria@ucsd.edu cranial blood supply, brainstem, and cranial nerves [1]. Careful description of each injured component and the degree of distraction is important, because these details determine stability and management $[1,2]$. In this section, we will focus on $\mathrm{C} 2$ fractures, which account for $17-20 \%$ of cervical spine fractures $[3,4]$. There are three main $\mathrm{C} 2$ fracture types: odontoid fractures, traumatic spondylolysis, and, less commonly, vertebral body/lateral mass fractures [2, 3].

\section{Key Point}

- Odontoid fractures are the most common C2 fractures, followed by traumatic spondylolisthesis; both fracture types have clinically relevant classification schemes.

Approximately 59\% of C2 fractures involve the odontoid process $[3,4]$. Mortality of C2 fractures in patients 65 years and older is substantial-approximately $15 \%$ at 30 days and $34 \%$ and 1 year [5]. The most common mechanism is motor vehicle accident, but in older patients even low energy trauma can result in odontoid process fractures [5]. There are three types of odontoid fractures as classified by Anderson and D'Alonzo (Fig. 13.1) [2, 6]. Type I (1-3\%) fractures are through the odontoid tip and are likely due to alar ligament avulsion $[3,4,6]$. Because it is high in the odontoid, type I fractures are considered stable and typically heal with immobilization [3]. Type II (54-60\%) fractures are at the junction of the odontoid and the vertebral body, and fractures with $>6 \mathrm{~mm}$ displacement, comminution, and/or concomitant ligamentous injury have a greater risk of nonunion and likely require surgical management $[3,7,8]$. Hadley et al. also proposed a type IIA odontoid fracture with additional chip fracture fragments at the dens base, either anteriorly or posteriorly (Fig. 13.2) [8]. These fractures are unstable and tend toward nonunion [8]. Patients older than 50 years are at greater risk 

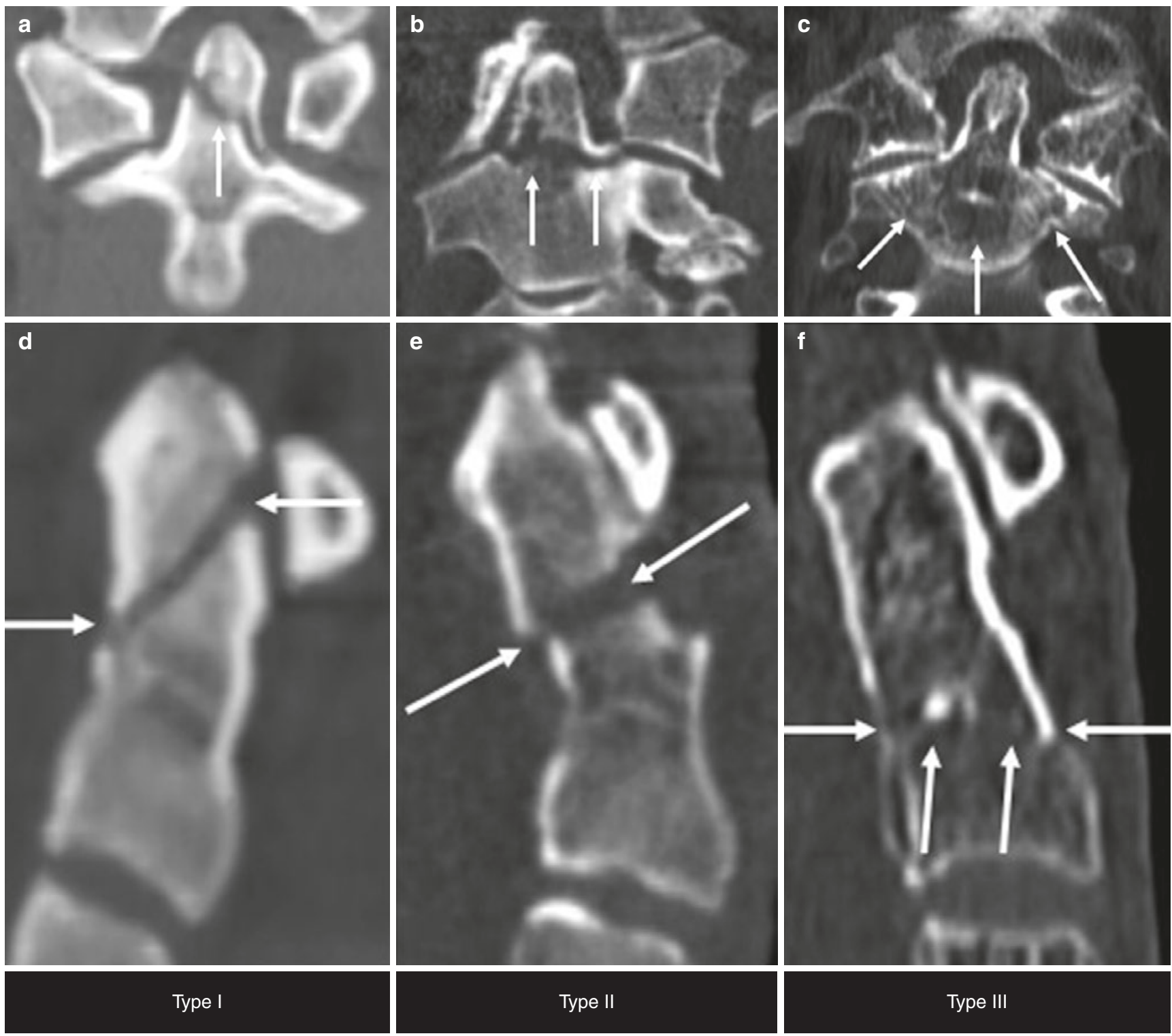

Fig. 13.1 Odontoid fracture classification. (a, b) A 39-year-old male injured in motor vehicle accident. Coronal (a) and sagittal (b) images of the $\mathrm{C} 2$ vertebral body demonstrate a fracture through the tip of the $\mathrm{C} 1$ vertebral body, consistent with a type I odontoid fracture. (c, d) A 69-year-old man who fell in the bathroom. Coronal (c) and sagittal (d) images of the $\mathrm{C} 2$ vertebral body demonstrate a fracture with less than $6 \mathrm{~mm}$ of displacement at the junction of the odontoid and $\mathrm{C} 2$ vertebral

body, consistent with a type II odontoid fracture. The patient was neurologically intact and managed nonoperatively. (e, f) A 76-year-old woman with osteogenesis imperfecta who fell while transferring to a commode. Coronal (e) and sagittal (f) images of the $\mathrm{C} 2$ vertebral body demonstrate an oblique fracture through the cancellous portion of the C2 vertebral body (arrows), consistent with a type III odontoid fracture. This fracture was stable and healed with nonoperative management

for nonunion [9]. Type III (39-42\%) fractures are through the cancellous bone of the vertebral body $[4,6]$. They are generally stable and heal with halo immobilization $[3,4]$.

Traumatic spondylolisthesis is the second most common C2 fracture (approximately 38\%) [1]. This fracture is commonly called the "hangman's fracture," although forensic research suggests that this fracture occurred in less than $10 \%$ of judicial hangings; currently it is most commonly due to motor vehicle accidents $[10,11]$. There are five injury patterns as originally defined by Effendi and later revised by

Levine and Starr (Fig. 13.3) [12]. The degree of distraction and anterior translation should be described, as these determine fracture stability [12]. Type I (65-72\%) fractures are the most common, followed by type II (27-28\%) (Fig. 13.4) and type III (1-7\%) fractures [3, 13]. Type I and type II may appear similar on supine imaging, and upright radiographs may reveal distraction $[1,14]$. Type IIA has more distraction than translation and therefore a greater degree of kyphosis when compared with type II $[1,14]$. Neurologic injury is uncommon and only occurs if there is spinal canal narrowing, 

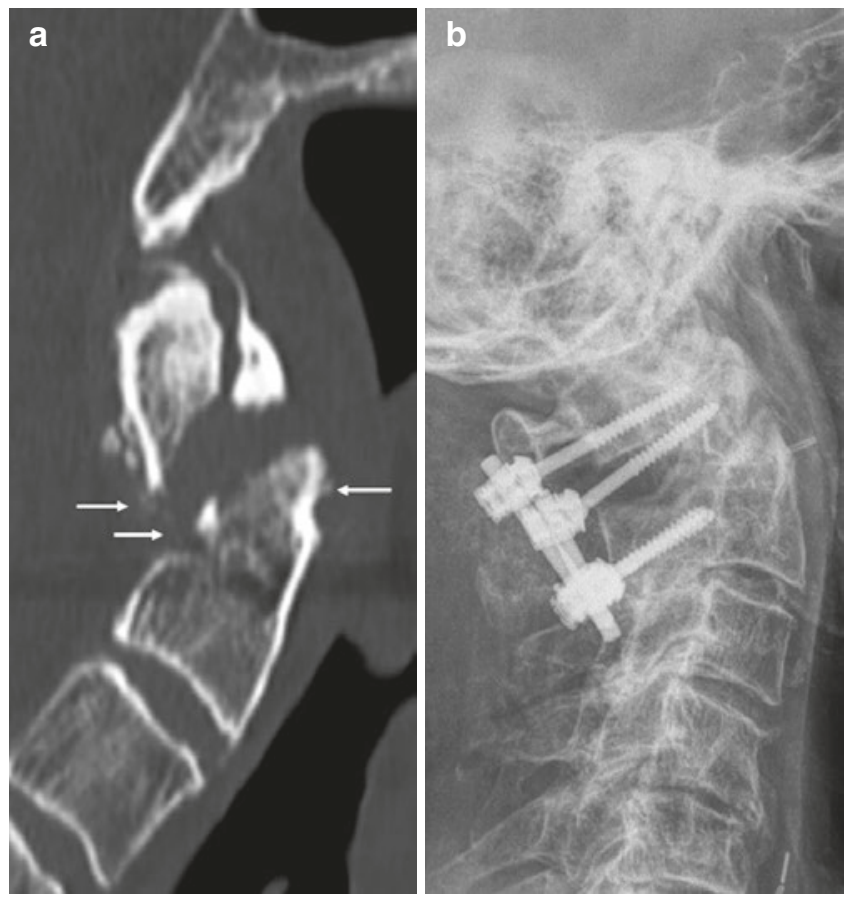

Fig. 13.2 An 85-year-old man with neck pain after unwitnessed fall. (a) Sagittal CT image demonstrates a displaced fracture through the base of the odontoid process, with more than $6 \mathrm{~mm}$ of displacement and small chip fragments anteriorly and posteriorly (arrows), consistent with a type IIA fracture. This fracture is unstable and requires surgical management. (b) Subsequent lateral radiograph demonstrates posterior C1-C2 spinal fusion which may occur in type IA (33\%) or type III (60\%) injuries [1]. The other fracture types generally result in spinal canal widening [1].

Vertebral body/lateral mass fractures (22\%) are the least common, and the vast majority are managed nonoperatively with good result [3]. C2 body fractures are difficult to detect on radiographs, and Pellei described a useful finding called the "fat" C2 sign to improve sensitivity (Fig. 13.5) [15]. The C2 vertebral body appears "fat" (increased anteroposterior diameter) when there is a displaced vertebral body fracture fragment and suggests that the fracture is unstable requiring further imaging. This sign may be the result of any fracture involving the $\mathrm{C} 2$ vertebral body, including a type III dens fracture or an atypical traumatic spondylolysis.

\subsection{Mid to Lower Cervical}

Mid to lower cervical spine (subaxial) injuries represent 65\% of cervical spine fractures and are classified based on mechanism of injury: flexion compression, extension compression, vertical compression, flexion-distraction, extensiondistraction, and lateral flexion or rotation [12]. The Subaxial Injury Classification and Scoring (SLIC) system incorporates imaging (CT and MRI) and clinical findings into a single score, placing the patient in nonsurgical (total SLIC
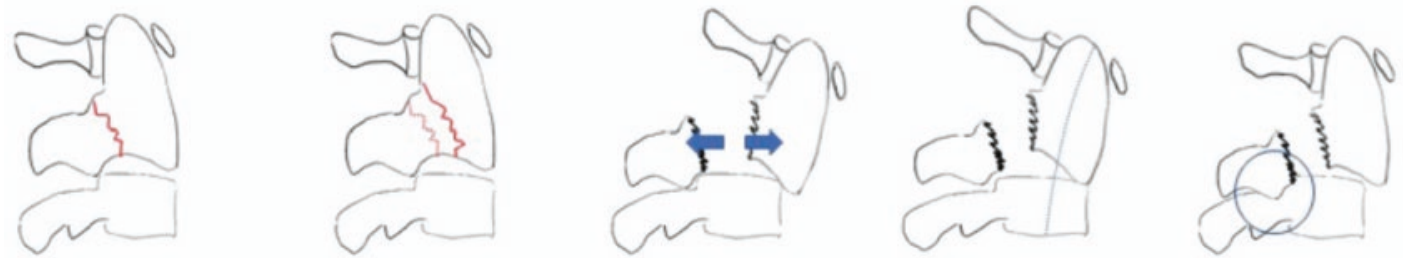

\begin{tabular}{|c|c|c|c|c|c|}
\hline & Type I & Type IA & Type II & Type IIA & Type III \\
\hline Forces & $\begin{array}{l}\text { Hyperextension } \\
\text { Axial loading }\end{array}$ & $\begin{array}{l}\text { + Lateral } \\
\text { bending }\end{array}$ & + Flexion & $\begin{array}{c}+ \text { Flexion and } \\
\text { distraction }\end{array}$ & \\
\hline Displacement & $<3 \mathrm{~mm}$ & & $>3 \mathrm{~mm}$ & & \\
\hline \multirow[t]{2}{*}{$\begin{array}{l}\text { Associated } \\
\text { injuries }\end{array}$} & & Vertebral body & \multicolumn{3}{|c|}{$\begin{array}{c}\text { C2-C3 intervertebral disc } \\
\text { Posterior longitudinal ligament }\end{array}$} \\
\hline & & & & & $\begin{array}{l}\text { C2-C3 facet } \\
\text { dislocation }\end{array}$ \\
\hline Un/Stable & Stable & Unstable & Unstable & Unstable & Unstable \\
\hline Management & $\begin{array}{l}\text { Ambulatory } \\
\text { immobilization }\end{array}$ & $\begin{array}{l}\text { Ambulatory } \\
\text { immobilization }\end{array}$ & $\begin{array}{c}\text { Halo } \\
\text { Immoblization }\end{array}$ & Surgical & Surgical \\
\hline
\end{tabular}

Fig. 13.3 Traumatic spondylolisthesis classification 



Fig. 13.4 A 62-year-old woman with multiple sclerosis who presents status post fall. (a, b) Sagittal CT images of the cervical spine demonstrate bilateral C2 pars interarticularis fractures. (c) Sagittal CT image of the cervical spine demonstrates anterolisthesis (white arrow) and posterior displacement of the $\mathrm{C} 2$ posterior elements (black arrow). (d)

Axial CT image of the cervical spine demonstrates bilateral comminuted fractures extending into the vertebral foramina. There was no evidence for vertebral artery injury. This fracture is atypical, but most closely approximates by a type II fracture 


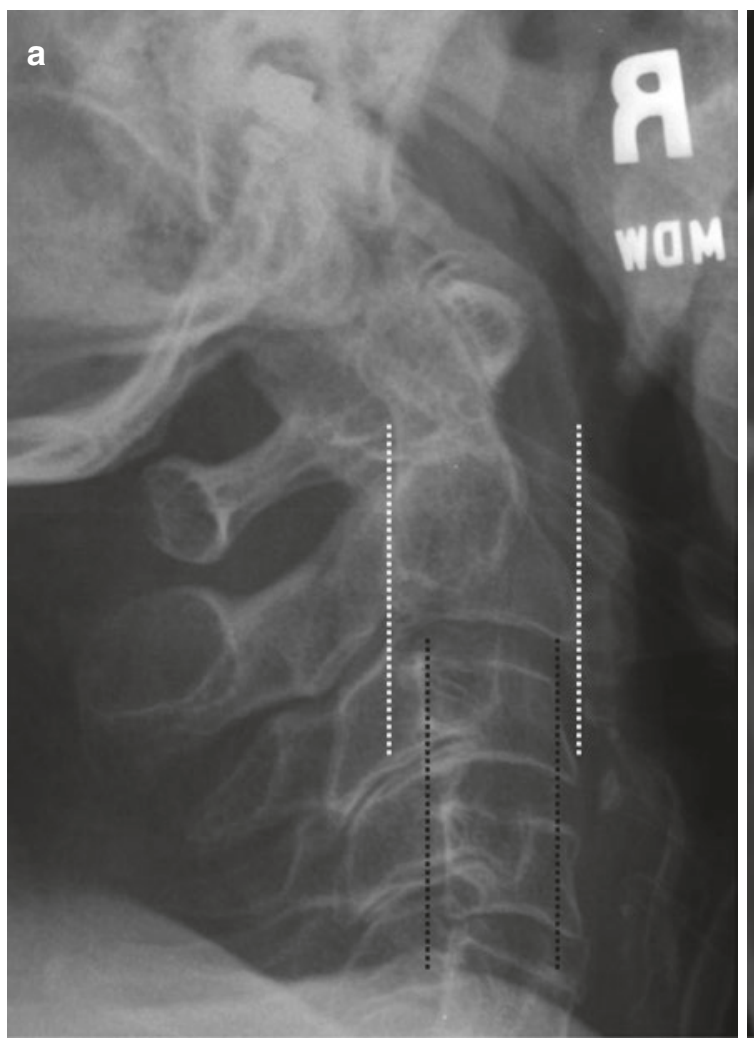

Fig. 13.5 A 79-year-old woman who was T-boned in a motor vehicle accident. (a) Lateral radiograph of the cervical spine demonstrates wider anterior-posterior (AP) diameter of the $\mathrm{C} 2$ vertebral body (white

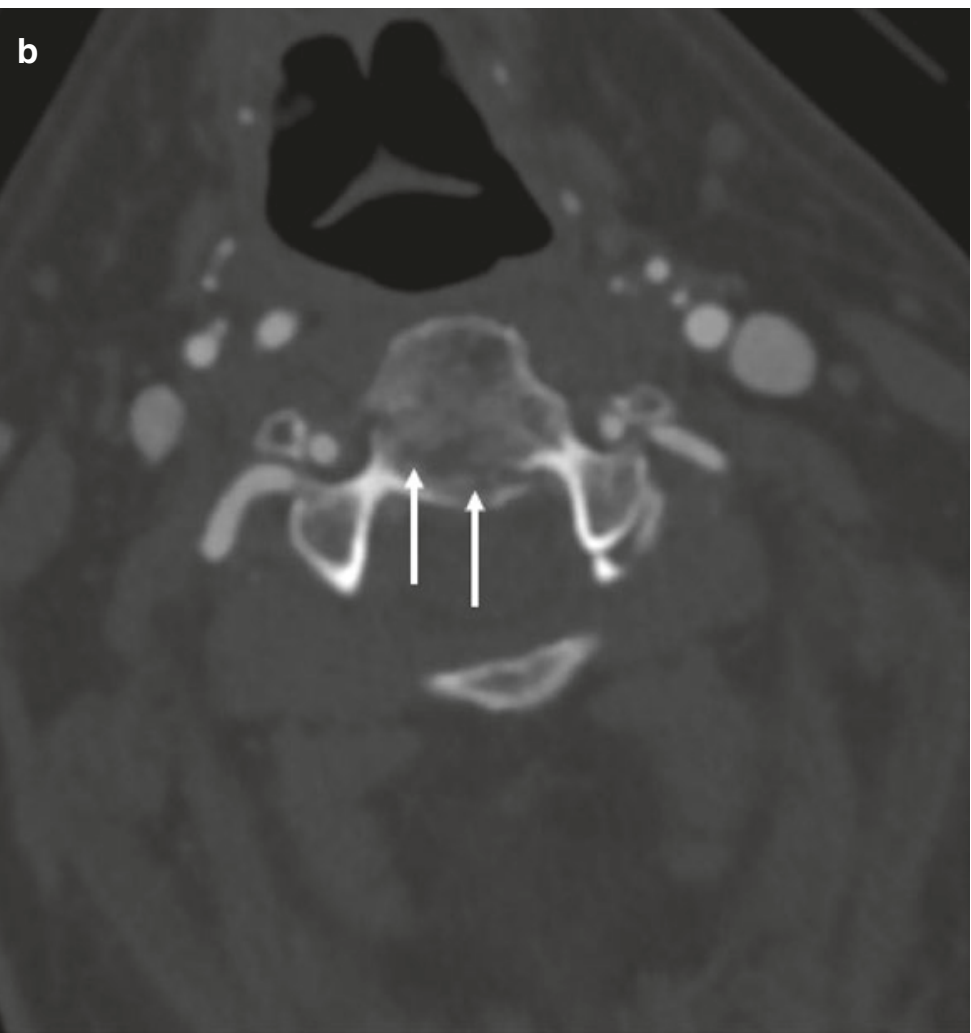

dotted line) compared to the AP diameter of the $\mathrm{C} 3$ vertebral body (black dotted line). (b) Axial CT image through the level of C2 demonstrates a mildly displaced vertebral body fracture score $\leq 3)$, indeterminate $(=4)$, or surgical $(\geq 5)$ management categories (Table 13.1) [12]. Each injured level receives a separate score. The abnormality with the highest score is used for the scoring system, i.e., fractures with distraction and translation are scored as translation $[16,17]$.

\section{Key Point}

- The Subaxial Injury Classification and Scoring (SLIC) system is helpful for framing evaluation of mid to lower cervical spinal injuries.

Familiarity with this scoring system is important for radiologists interpreting these studies, because communication of findings using this terminology enhances communication with the trauma surgeons. Patients with a high SLIC score typically require surgical management to relieve cord compression and stabilize the spine (Fig. 13.6). Conversely, patients with a low SLIC score can be managed conservatively (Fig. 13.7).
Table 13.1 Subaxial Injury Classification and Scoring (SLIC) system $[2,35]$

\begin{tabular}{l|l|}
\hline Category & Score \\
\hline $\begin{array}{l}\text { Neurologic status } \\
\text { Intact }\end{array}$ & 0 \\
\hline $\begin{array}{l}\text { Root injury } \\
\text { Complete cord injury }\end{array}$ & 1 \\
\hline $\begin{array}{l}\text { Incomplete cord injury } \\
\text { Incomplete cord injury with ongoing cord compression }\end{array}$ & 2 \\
\hline $\begin{array}{l}\text { Morphology } \\
\text { No abnormality }\end{array}$ & 4 \\
\hline $\begin{array}{l}\text { Compression } \\
\text { Burst }\end{array}$ & 0 \\
\hline $\begin{array}{l}\text { Distraction (facet diastasis }>2 \text { mm, facet subluxation with } \\
<50 \% \text { overlap, posterior disk space widening and }>11^{\circ}\end{array}$ & 1 \\
$\begin{array}{l}\text { angulation) } \\
\text { Rotation (anterolisthesis }>3.5 \text { mm but }<50 \% \text { of caudal } \\
\text { vertebral body anterior-posterior (AP) dimension) or } \\
\text { translation (anterolisthesis }>3.5 \text { mm and }>50 \% \text { of caudal } \\
\text { vertebral body anterior-posterior (AP) dimension) }\end{array}$ & 2 \\
\hline $\begin{array}{l}\text { Discoligamentous complex } \\
\text { Intact }\end{array}$ & 4 \\
\hline $\begin{array}{l}\text { Indeterminate } \\
\text { Disrupted }\end{array}$ & \\
\hline & 0 \\
\hline & 1 \\
\hline
\end{tabular}





Fig. 13.6 An 18-year-old man who was a restrained passenger in a motor vehicle accident, where his car collided with another vehicle and rolled into a ditch. Unfortunately, the patient did not survive the accident and passed away several days later. (a) Lateral radiograph demonstrates anterolisthesis of the widened $\mathrm{C} 2-\mathrm{C} 3$ disk space, comminuted fracture fragments in the disk space, probably from the $\mathrm{C} 3$ superior endplate, and bilateral perched facets. (b) Sagittal T2 fat-suppressed image through the midline of the upper cervical spine demonstrates complete separation of the $\mathrm{C} 2$ inferior endplate from the $\mathrm{C} 2-\mathrm{C} 3$ intervertebral disk, anterior longitudinal and posterior longitudinal ligament injury, and interspinous ligament injuries. There is extensive anterior and posterior soft tissue hemorrhage. There is also hemorrhage within the swollen spinal cord, with ongoing compression of the cord by the C3 vertebral body. The patient's clinical examination was consistent with complete cord injury, but given the ongoing cord compression, the SLIC neurologic status score is 4. (c) Sagittal CT image through the midline of the upper cervical spine demonstrates anterolisthesis $>3.5 \mathrm{~mm}$ but less than $50 \%$ of the $\mathrm{C} 3$ vertebral body. For the morphology category, the facets are subluxated $>50 \%$ of the articular surfaces; however, there is also $>3.5 \mathrm{~mm}$ anterolisthesis, which is $<50 \%$ of the caudal vertebral body AP dimension, resulting in a SLIC morphology score of 4 . The discoligamentous complex is disrupted, consistent with a SLIC score of 2 . The total SLIC score is 10 , which would warrant surgical management for the fracture

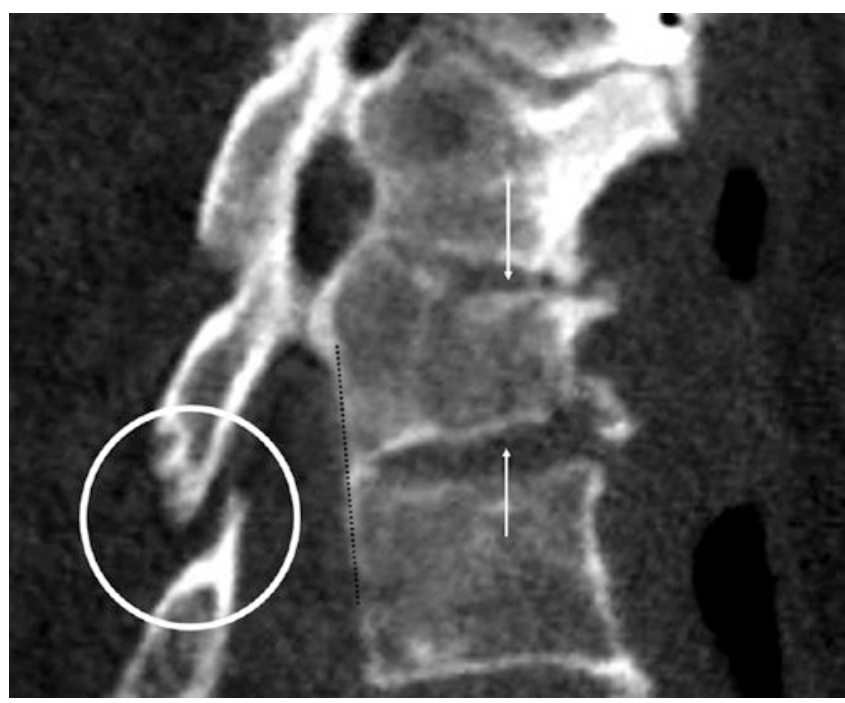

Fig. 13.7 A 70-year-old man status post fall with head strike against a wall. Sagittal CT image demonstrates a comminuted C7 vertebral body fracture with compression (arrows). The fracture does not extend to the vertebral body posterior margin. There is bilateral facet subluxation (only one side shown; circle). There is no listhesis (dotted line). The patient had no neurologic deficits (SLIC neurologic status score 0). The facet joints are subluxated bilaterally, but there is no facet diastasis or posterior disk space widening to indicate discoligamentous description. There is compression of the vertebral body, consistent with a SLIC morphology score of 1 . The total SLIC score is low and the patient was successfully treated with conservative management

\subsection{Upper Thoracic}

The T1-T10 vertebrae are relatively immobile as they are stabilized by a ring formed by the spine, ribs, and sternum so traumatic injuries of this region are less common than at the more mobile cervical and thoracolumbar regions. In young adults, less than $25 \%$ of all thoracic fractures affect T1-T10, typically following a fall, motor vehicle accident or seizure [18]. The most common fracture pattern is superior endplate compression resulting in paraspinal swelling, anterior height loss, and disruption of the anterior cortex and subchondral bone, without posterior height loss, retropulsed bone, or malalignment. Mild height loss alone lacks specificity as it can be physiologic or due to Scheuermann disease, which is associated with disk height loss, Schmorl nodes, and kyphosis [19]. Impacted subchondral trabecular bone is more specific, appearing as a transverse zone of sclerosis paralleling the endplate that becomes more apparent as the fracture heals. Mild compression fractures are stable, but those with greater than $40 \%$ height loss can result in delayed kyphotic deformity, particularly if there are multiple contiguous fractures [20].

While fractures of the upper thoracic spine in young patients are typically the result of significant force, upper thoracic fractures in elderly osteoporotic patients often result from trivial injury and can be challenging to visualize on 
radiographs. Osteoporotic thoracic fractures are common; $18 \%$ of white women older than 50 and $78 \%$ of white women older than 90 years have at least one thoracic compression fracture, typically in conjunction with additional fractures in the lumbar region [21]. Bone fragility allows the fracture to propagate easily to the posterior vertebral body margin, resulting in greater height loss and retropulsion of bone into the canal.

In elderly patients, distinguishing osteoporotic fractures from pathologic fractures can be challenging. Findings sug-

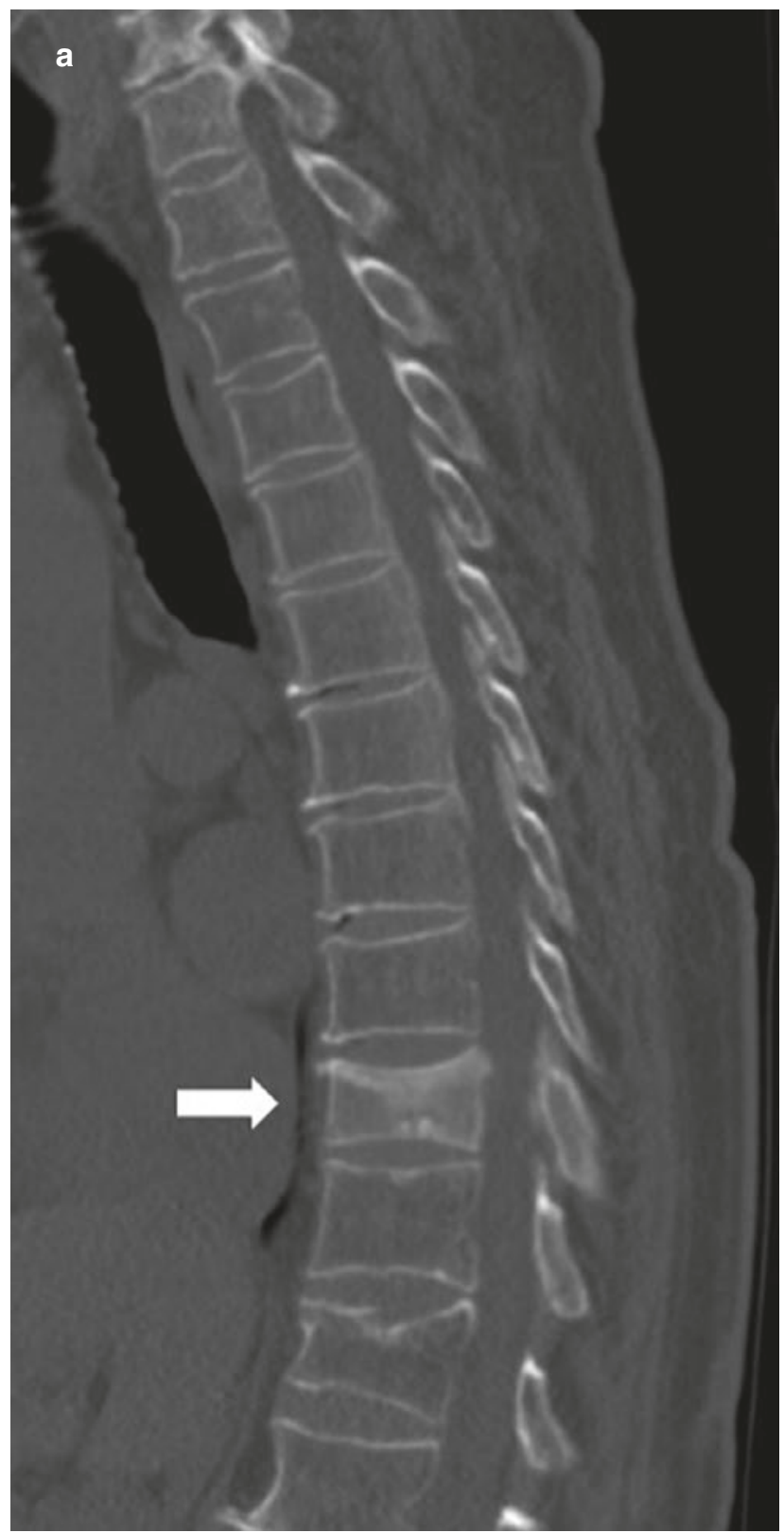

Fig. 13.8 A 74-year-old male with history of prostate cancer. Sagittal CT (a) and T1-weighted MR (b) of the thoracic spine show a pathologic fracture at T10 (arrows) and a benign osteoporotic compression fracture at $\mathrm{T} 12$. The $\mathrm{CT}$ shows subtle increased density at T10 and cortical blurring of the edges of the spinous process. The MR shows complete marrow replacement of the T10 vertebral body and spinous process at T10, gesting underlying neoplasia include isolated fractures above $\mathrm{T} 7$, preferential posterior height loss or bulging of the posterior cortex, cortical erosion of the vertebral body or posterior elements, soft tissue mass, and diffuse replacement of the vertebral body fat signal, whereas a simple transverse fracture line with band-like partial marrow replacement limited to the upper or lower half of the vertebral body and the presence of a linear cleft of fluid or gas favor a benign process [22] (Fig. 13.8). MR techniques that identify regions of restricted diffusion within neoplastic tissue and phase imag-



mild height loss and a convex contour at the posterior vertebral margin, and encroachment on the posterior epidural space by soft tissue extension from the posterior elements resulting in stenosis. In contrast, the chronic osteoporotic fracture at T12 shows normal fatty marrow signal, a more angular deformity of the superior endplate, and an intact posterior margin 
ing to identify microscopic fat within benign lesions are useful in equivocal cases though some fractures remain indeterminate, requiring biopsy [23].

\section{Key Point}

- Upper thoracic fractures in elderly osteoporotic patients can be difficult to distinguish from pathologic fractures. Morphologic features of the fracture and adjacent soft tissues are augmented by advanced MR imaging techniques to help determine if the fracture is benign or malignant.
Severe upper thoracic injuries such as burst fractures with retropulsed bone, anterior and posterior distraction injuries, and fracture-dislocation are uncommon. Fracturedislocation of the upper thoracic spine is the result of combined hyperflexion, axial loading, and rotary/shear forces resulting in extensive ligament disruption, complex fractures, and spinal malalignment including translation, rotation, and telescoping of vertebrae [23] (Fig. 13.9). In such injuries, the disproportionately small ratio of the spinal canal to the cord in the upper thoracic region leads to a high risk of neurologic deficit. Soft tissue hemorrhage and associated visceral and mediastinal injuries are common [18]. CT and MR are needed to fully characterize

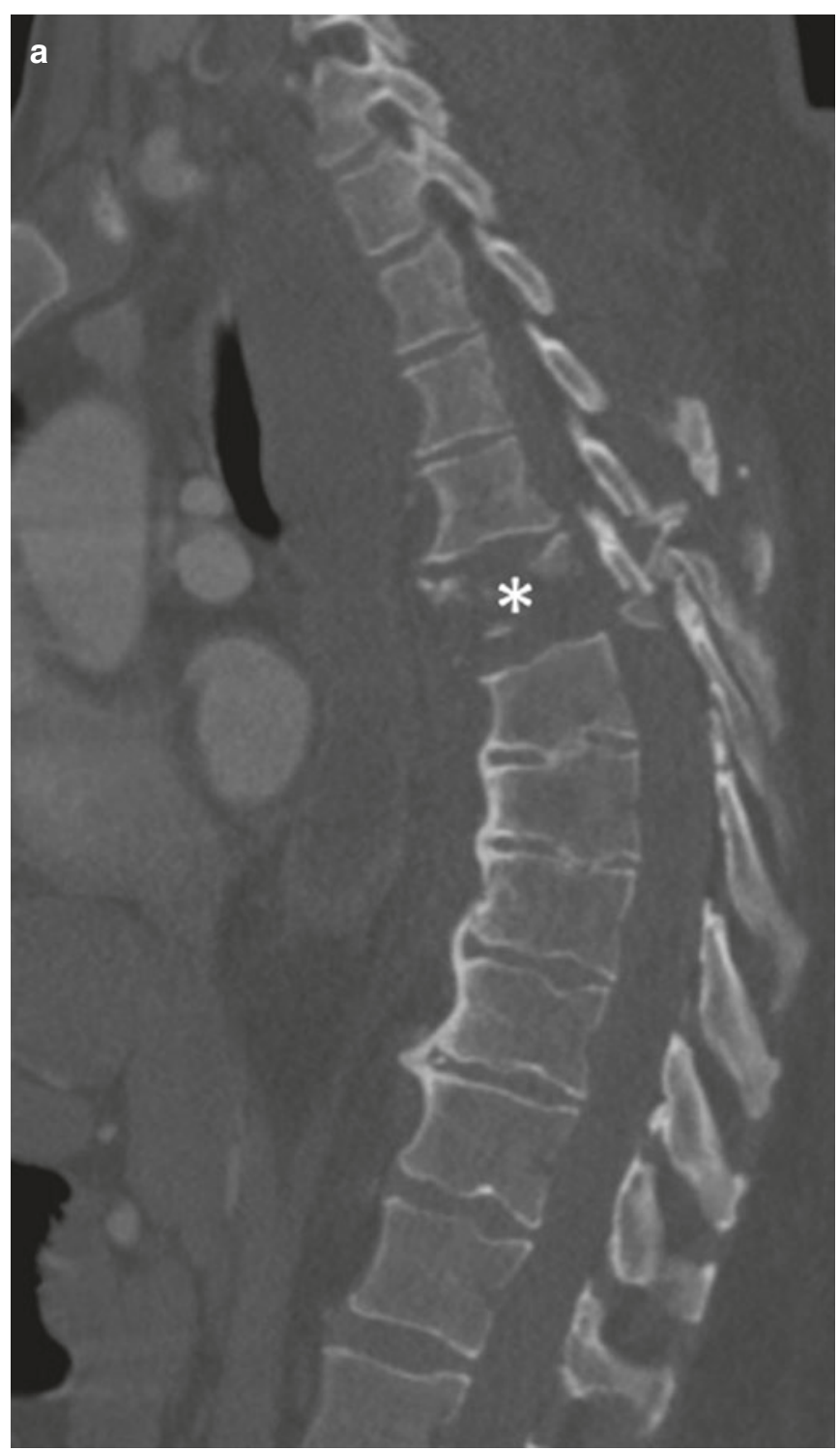

Fig. 13.9 A 56-year-old involved in all-terrain vehicle accident with fracture-dislocation of the upper thoracic spine resulting in paraplegia. Sagittal CT (a) of the thoracic spine illustrates multiple upper thoracic fractures with comminution of the T6 body (asterisk), malalignment

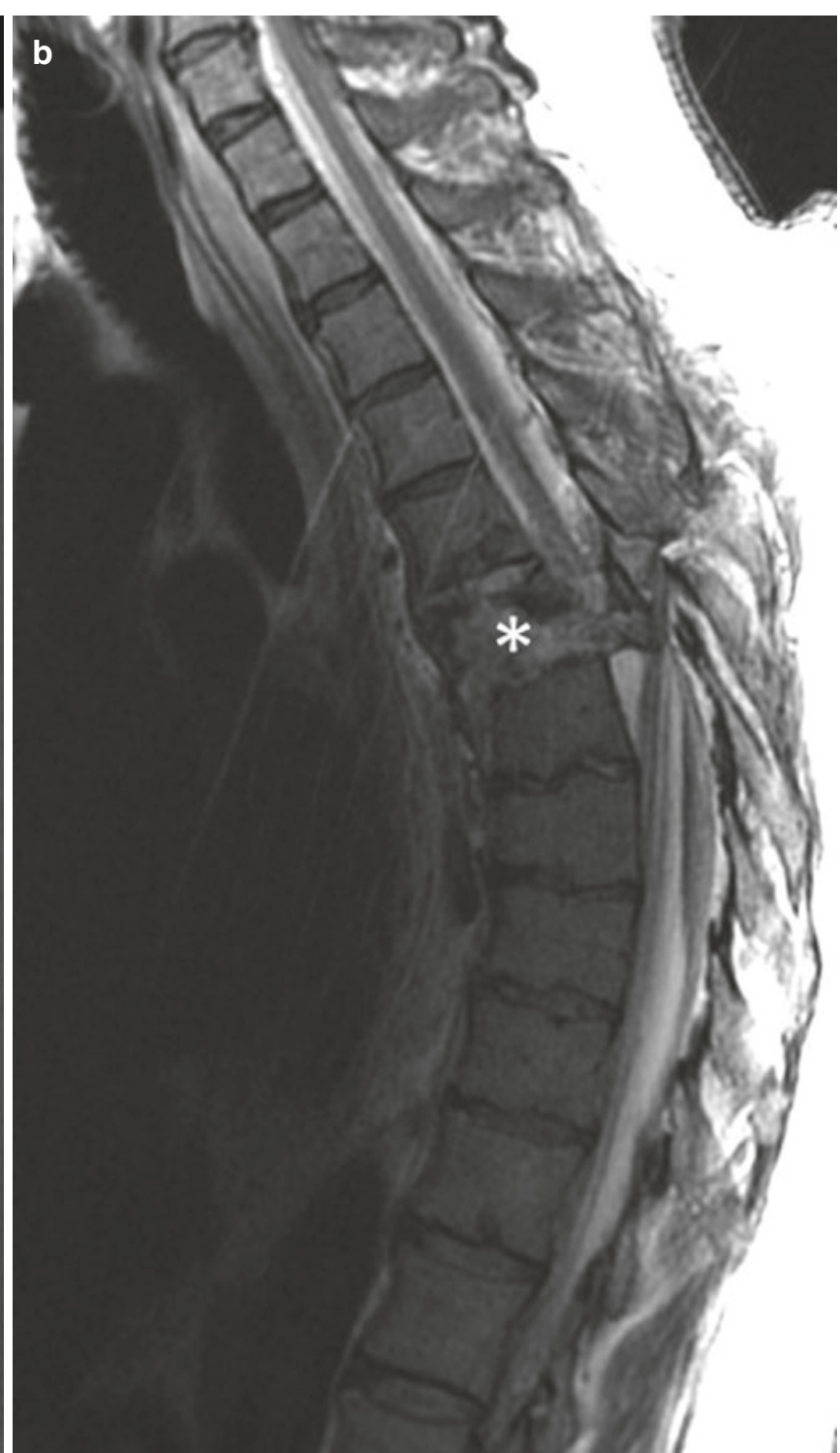

with anterior shift of $\mathrm{T} 5$ relative to $\mathrm{T} 7$, disruption of the posterior elements with facet dislocation, and large bone fragments encroaching on the spinal canal. (b) The corresponding T2-weighted sagittal MR shows disruption of the thoracic cord at the injury level 
these complex injuries, affording detailed assessment of fractures, ligaments, neural elements, and paraspinal soft tissues.

\subsection{Thoracolumbar}

The thoracolumbar region is commonly injured, representing the second most common site of spinal trauma following the lower cervical spine. Modern classification systems of spinal injury are based on systems initially developed to organize thoracolumbar injuries according to injury mechanism, using fracture morphology and degree of displacement to assess stability and plan management. The initial system widely used was the Denis classification that divided the spine into anterior, middle, and posterior columns, emphasizing the role of the middle column (posterior vertebral margin, posterior longitudinal ligament, and posterior annulus) in maintaining stability [24]. Denis classified thoracolumbar injuries into (1) compression fracture limited to the anterior column; (2) burst fracture involving anterior and middle columns; (3) seat belt injury resulting from distraction of the middle and posterior columns from distraction; and (4) fracture-dislocation with disruption of all three columns. This classification was based on radiographs and did not account for many spinal injuries, particularly those where the anterior spine was compressed while the posterior ligaments failed by distraction, a pattern well appreciated on MR imaging. Current classification systems have expanded Denis' system to offer a more comprehensive classification and account for more injury patterns and also include clinical parameters. Currently, the most widely used thoracolumbar injury classification is based on combining features of the AO-Magerl classification (Arbeitsgemeinschaft für Osteosynthesefragen) and TLICS (Thoracolumbar Injury Classification and Severity Score) system $[16,20]$. The AO/TLICS system, based on a consensus of international spine surgeons, classifies fracture morphology into three main patterns: type A (compression), type B (tension band disruption, either anterior or posterior), and type $\mathrm{C}$ (displacement/translation) with several subtypes in the first two categories. The grading of morphology relies on accurate assessment of both bone and ligament injury and emphasizes the utility of CT and MRI for assessment of thoracolumbar trauma [25].

\section{Key Point}

- The AO/TLICS classification of thoracolumbar injuries is based on fracture morphology as defined by imaging, categorizing fractures into those caused by compression, distraction, or translation.
The fracture morphology score is combined with a grading of neurologic status and a description of patient-specific modifiers that affect the likelihood of surgery to help select management [16]. This classification has similar considerations as the SLIC grading system of cervical trauma previously discussed.

\subsubsection{Type A: Compression Injuries}

The most common injury mechanism is compression which produces a range of fracture morphologies that include superior and inferior endplate impaction, anterior wedging of varying severity, burst fractures, and sagittal splitting of the vertebral body. Similar to the remainder of the spine, mild compression fractures result in anterior height loss, buckling of the cortex, and endplate comminution producing bandlike sclerosis adjacent to the fractured endplate. On CT, these appear as an arc of irregular bony fragments displaced circumferentially at the level of the endplate. Posterior vertebral and intervertebral disk height are preserved and there is no listhesis. Compression fractures with greater than $40 \%$ height loss, particularly in the setting of multiple contiguous fractures and posterior ligament sprain may require prolonged bracing [26]. Severe compression fractures showing with greater than $70 \%$ height loss may require posterior stabilization to avoid kyphotic deformity. Unlike simple compression fractures, burst fractures involve the posterior vertebral body margin, leading to posterior vertebral height loss and retropulsed bone in the spinal canal. The thoracolumbar region is the most common site of spinal burst fractures, and such injuries make up 16\% of all spinal injuries encountered at a trauma center. CT scanning is the most efficient method for characterizing the fracture, identifying associated posterior element fractures and evaluating bone encroaching on the spinal canal (Fig. 13.10).

\subsubsection{Type B: Distraction (Tension Band) Injuries}

The vast majority of distraction injuries of the thoracolumbar spine results from flexion with the resulting tensile force, leading to purely osseous, purely ligamentous, or combined bony and soft tissue injury starting at the posterior spine allowing separation between the posterior elements, followed by anterior soft tissue injury or vertebral fracture. The classic horizontally oriented Chance fracture is one example of a distraction injury, but there is a broad spectrum of distraction injury patterns depending on whether the injury is primarily ligamentous or osseous and whether distraction affects the entire spine or only the posterior elements. Distraction injuries are associated with variable amounts of 

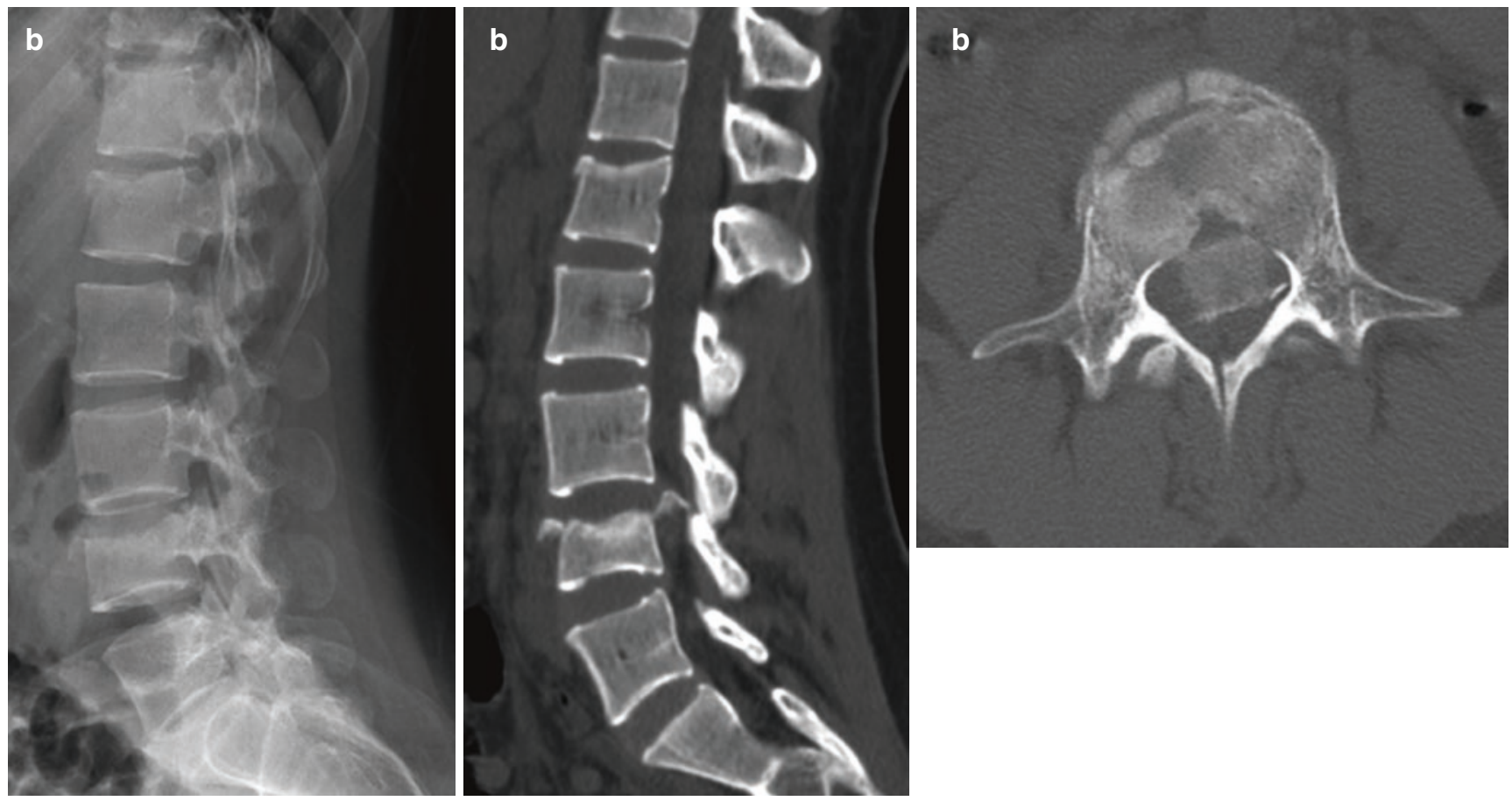

Fig. 13.10 A 28-year-old male with spinal injury after falling downstairs while intoxicated. The lateral radiograph (a) shows a mild superior endplate compression fracture of L1 with anterior cortical disruption and minimal height loss. Note the sclerosis below the superior endplate. The L4 vertebral body shows a burst fracture with height loss extending to the posterior vertebral margin. Sagittal CT (b) shows the fractures well and demonstrates a large rotated fragment of retropulsed bone within the spinal canal at L4. Axial CT (c) at L4 shows comminution of the vertebral body and a large fragment encroaching on the canal and neural elements. There is a sagittal split fracture through the posterior arch splaying of the posterior elements, which can be overlooked on radiographs and CT, particularly if the patient is recumbent [27]. In practice, many posterior tension band injuries with vertebral body fractures are easily confused for simple compression or burst fractures without MR imaging, which should be obtained whenever posterior ligament injury is suspected (Fig. 13.11). Anterior tension band injuries caused by hyperextension are far less common. The typical injury pattern is a horizontal fracture through the vertebral body or through an ossified disk in an elderly patient with underlying degenerative spinal fusion, leading to increased vertebral or disk height and lordosis [28].

\subsubsection{Type C: Displacement/Dislocation}

The most severe pattern of injury consists of displacement injuries with translation and/or rotation due to disruption of all the spinal ligaments, typically in association with fractures at both the anterior and posterior vertebra. Rib fractures and costotransverse dislocations often accompany these injuries.
Thoracolumbar displacement/dislocation injuries are associated with a high rate of neurologic deficit, with $50-90 \%$ of patients developing a permanent neurologic deficit.

\subsection{Lower Lumbar}

Pars interarticularis fracture or spondylolysis is a stress fracture of the bony arch connecting the upper and lower facet joints and occurs primarily at the L5 (85-95\%) and L4 $(5-15 \%)$ levels $[29,30]$. The prevalence is approximately $6 \%$, and many are asymptomatic, but spondylolysis can cause pain in athletes with high lower back stress (football, wrestling, dancing, weight lifting), particularly in the adolescent and preadolescent population [31,32]. Diagnosis on radiographs is best made on the oblique view, but radiographs have low sensitivity for stress injury and nondisplaced stress fractures (Fig. 13.12) [30, 33]. Flexion and extension views can detect motion and instability in the case of spondylolisthesis, which occurs in $50-81 \%$ of patients with spondylolysis [29, 31, 33]. 




Fig. 13.11 A 39-year-old female injured during motor vehicle accident. Sagittal CT (a) and T2-weighted MR (b) images of the lumbar spine show a fracture of the L1 vertebral body (asterisk) with height loss and a small bulge of retropulsed bone arising from the posterior margin of the upper endplate. An MR was obtained because of focal

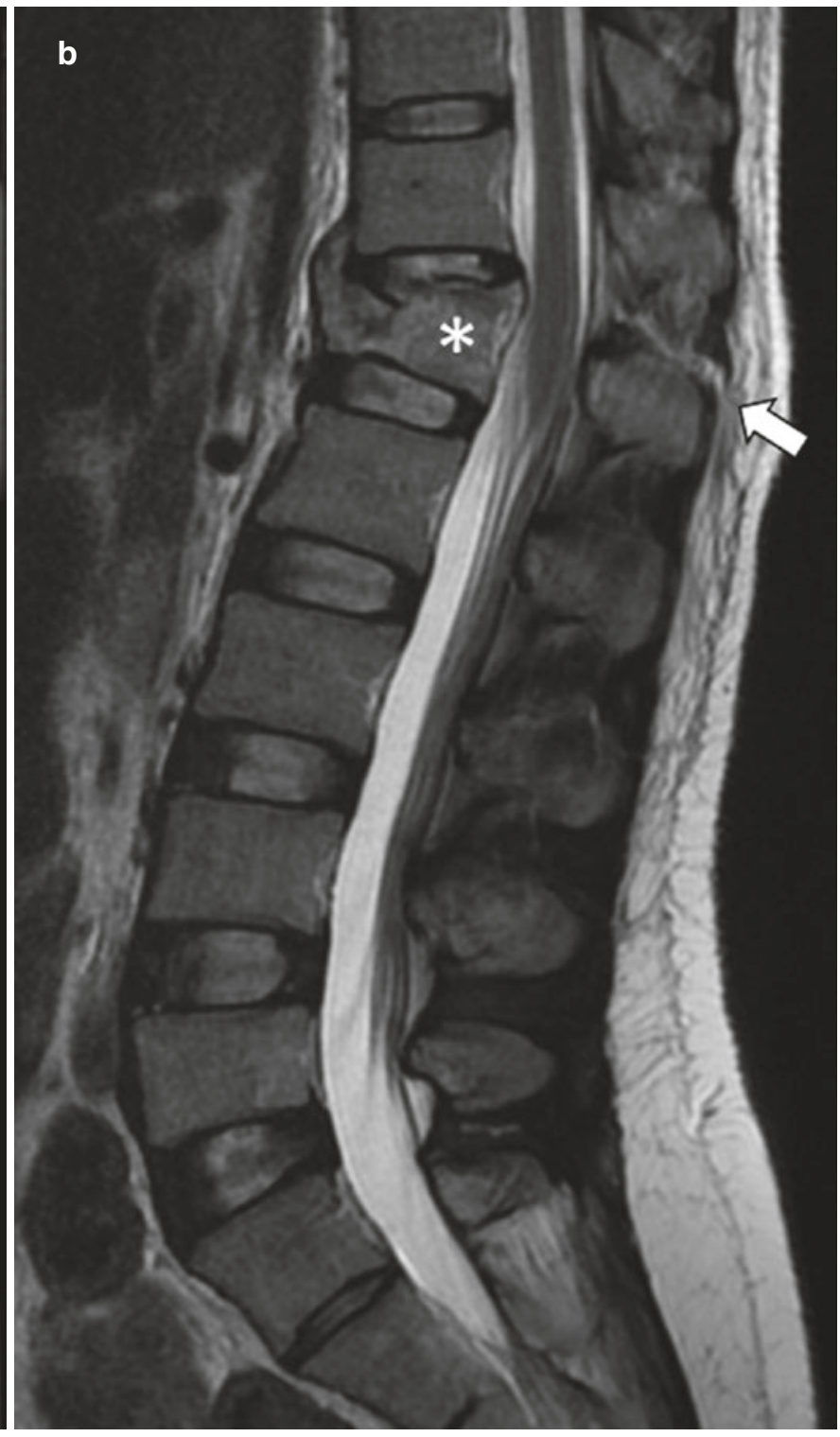

posterior pain and swelling and shows disruption of the supraspinous ligament (arrow), as well as edema in the T12/L1 interspace and loss of low signal at the ligamenta flava, indicating a tension band injury disrupting the posterior ligaments
A low threshold for obtaining a CT or MRI in patients with a suspicious clinical history and physical examination is recommended, because early detection and appropriate treatment (primarily rest and pain management) is important to prevent progression and more aggressive intervention [29]. CT has the highest sensitivity for fracture detection, while MRI has the advantage of detecting edema in early-stage injury (Fig. 13.13) [29]. Most patients are successfully managed conservatively, with surgery reserved for the $9-15 \%$ of cases that remain symptomatic after conservative care [29]. Because the condition can be asymptomatic, diagnostic steroid and anesthetic injection can be helpful to confirm the spondylolysis as the source of the patient's pain prior to surgery [34]. 


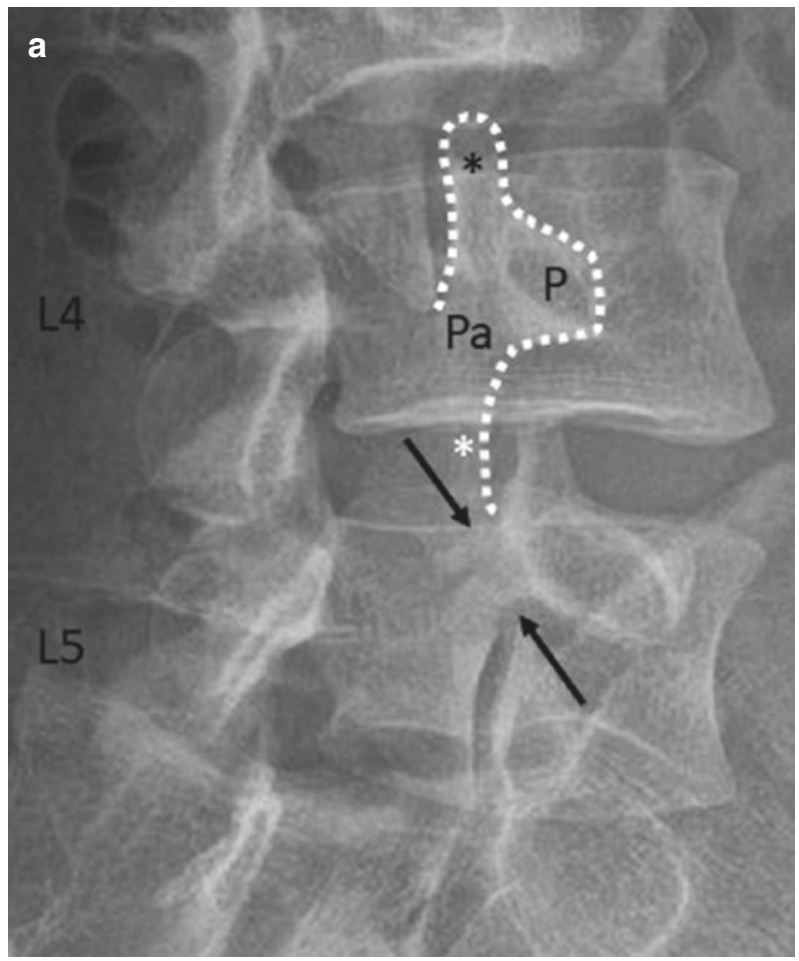

Fig. 13.12 A 24-year-old baseball player with acute on chronic unilateral left-sided lower back pain. (a) Oblique radiograph of the spine demonstrates the "Scottie dog" appearance of the vertebrae, outlined at the $\mathrm{L} 4$ level (dotted white line). $\mathrm{P}=$ pedicle, $\mathrm{Pa}=$ pars interarticularis, black $*=$ superior articular facet, white $*=$ inferior articular facet.

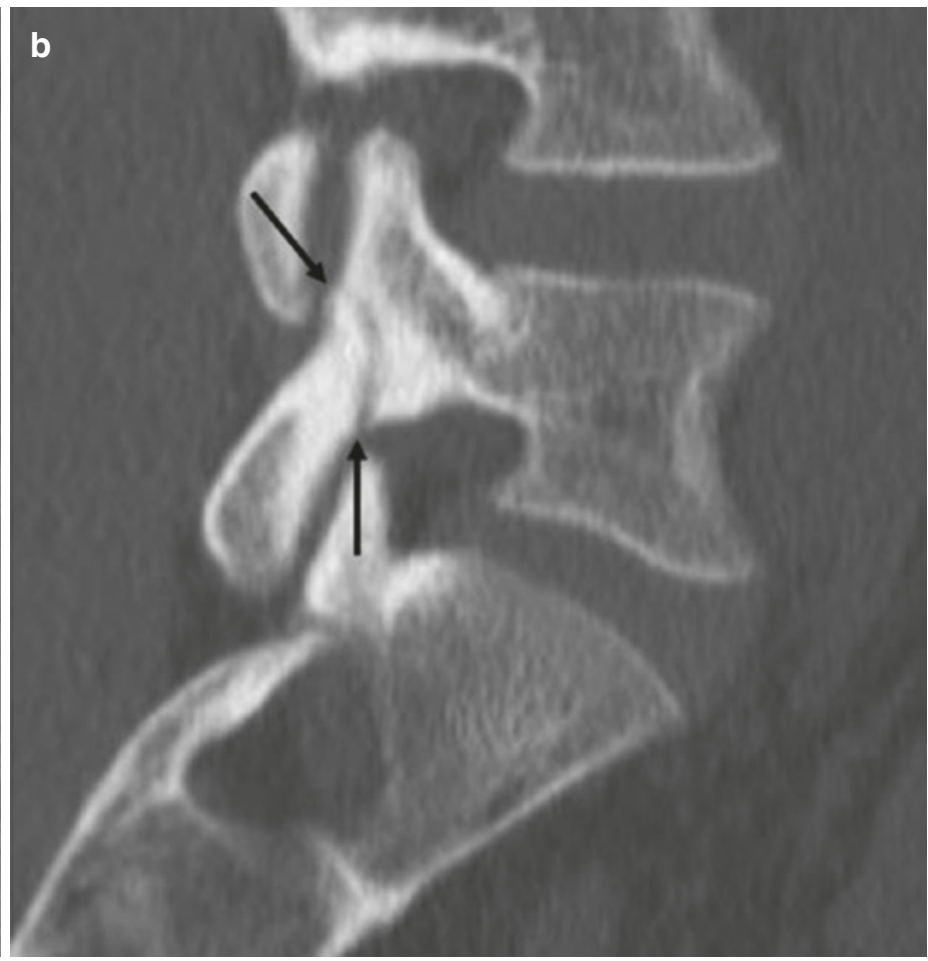

There is a resorption of the cortices and thinning of the pars interarticularis at L5; the fracture line is only partially visualized (arrows). (b) Sagittal CT image demonstrates a nondisplaced fracture of the left L5 pars interarticularis (arrows). There is surrounding sclerosis

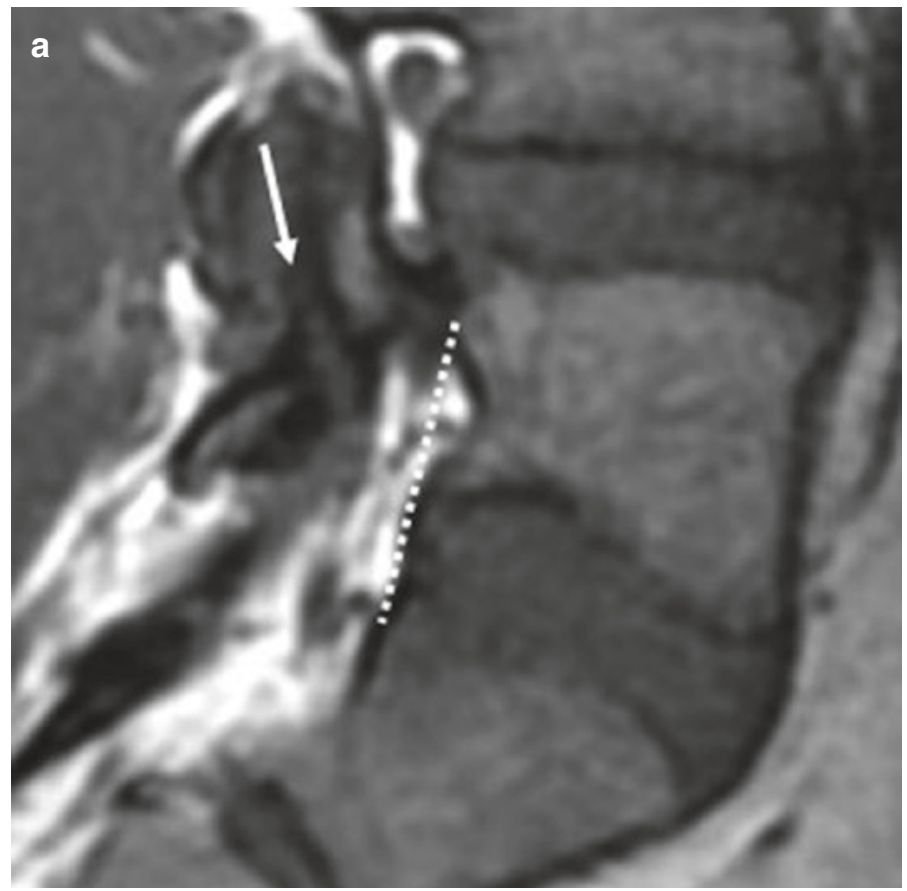

Fig. 13.13 An 18-year-old multisport collegiate athlete with acute on chronic left lower back pain since elementary school. (a) Sagittal T1 MRI image demonstrates nondisplaced left L5 pars interarticularis frac-

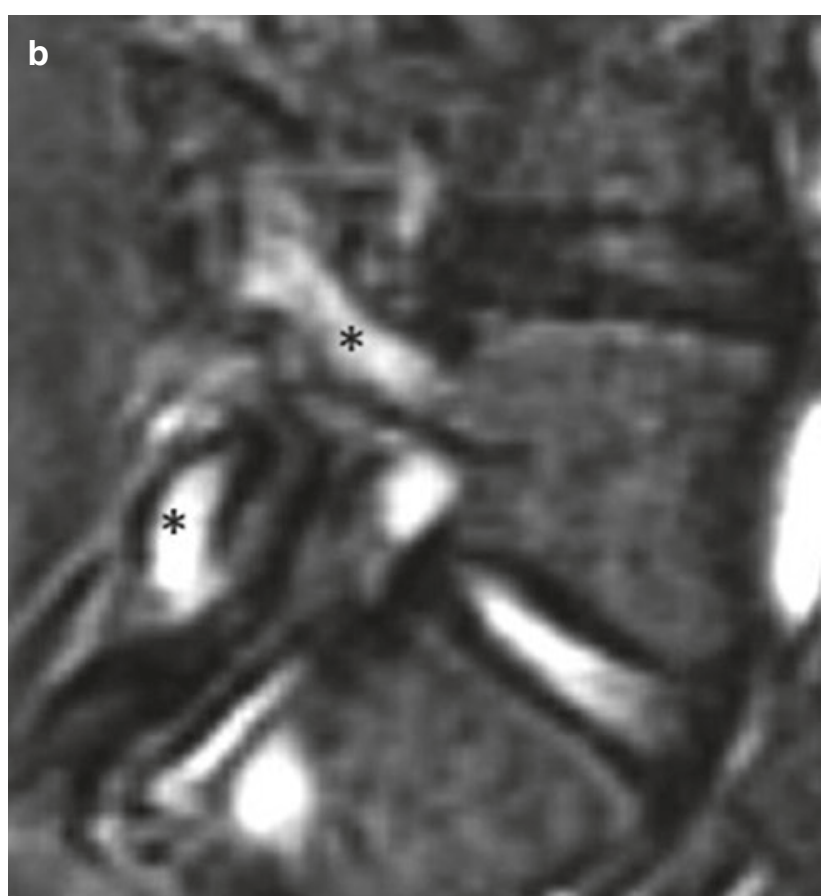

ture (arrow). There is no anterolisthesis (dotted line). (b) Sagittal T2 FS MRI image demonstrates marrow edema around the nondisplaced left L5 pars interarticularis fracture $(*)$ 


\subsection{Concluding Remarks}

Diagnostic imaging plays a critical role in identifying and classifying spinal injury. Understanding the unique features of each spinal segment and relevant classification systems can help the radiologist both with injury detection and with generating clinically relevant reports to help guide management.

\section{Take Home Messages}

- Injury affects different regions of the spine in different ways as a result of their unique anatomy and physiology. The most commonly injured regions are the lower cervical and thoracolumbar segments.

- Modern imaging and classification of spine trauma rely on cross-sectional imaging for diagnosis and classification of suspected spinal injury.

- Current classifications (SLIC and AO/TLICS) of spinal fractures are based on injury morphology as defined by imaging, combined with clinical parameters, to select suitable management.

\section{References}

1. Bransford RJ, Alton TB, Patel AR, Bellabarba C. Upper cervical spine trauma. J Am Acad Orthop Surg. 2014;22:718-29.

2. Dreizin D, Letzing M, Sliker CW, Chokshi FH, Bodanapally U, Mirvis SE, Quencer RM, Munera F. Multidetector CT of blunt cervical spine trauma in adults. Radiogr Rev Publ Radiol Soc N Am Inc. 2014;34:1842-65.

3. Greene KA, Dickman CA, Marciano FF, Drabier JB, Hadley MN, Sonntag VK. Acute axis fractures. Analysis of management and outcome in 340 consecutive cases. Spine. 1997;22:1843-52.

4. Pryputniewicz DM, Hadley MN. Axis fractures. Neurosurgery. 2010;66:68-82.

5. Shafafy R, Valsamis EM, Luck J, Dimock R, Rampersad S, Kieffer W, Morassi GL, Elsayed S. Predictors of mortality in the elderly patient with a fracture of the odontoid process. Bone Jt J. 2019;101-B:253-9.

6. Anderson LD, D'Alonzo RT. Fractures of the odontoid process of the axis. J Bone Joint Surg Am. 1974;56:1663-74.

7. Hadley MN, Browner C, Sonntag VK. Axis fractures: a comprehensive review of management and treatment in 107 cases. Neurosurgery. 1985; 17:281-90.

8. Hadley MN, Browner CM, Liu SS, Sonntag VK. New subtype of acute odontoid fractures (type IIA). Neurosurgery. 1988;22: $67-71$

9. Lennarson PJ, Mostafavi H, Traynelis VC, Walters BC. Management of type II dens fractures: a case-control study. Spine. 2000;25:1234-7.

10. James R, Nasmyth-Jones R. The occurrence of cervical fractures in victims of judicial hanging. Forensic Sci Int. 1992;54:81-91.
11. Ferro FP, Borgo GD, Letaif OB, Cristante AF, Marcon RM, Lutaka AS. Traumatic spondylolisthesis of the axis: epidemiology, management and outcome. Acta Ortop Bras. 2012;20:84-7.

12. Riascos R, Bonfante E, Cotes C, Guirguis M, Hakimelahi R, West C. Imaging of atlanto-occipital and atlantoaxial traumatic injuries: what the radiologist needs to know. Radiogr Rev Publ Radiol Soc N Am Inc. 2015;35:2121-34.

13. Effendi B, Roy D, Cornish B, Dussault RG, Laurin CA. Fractures of the ring of the axis. A classification based on the analysis of 131 cases. J Bone Joint Surg Br. 1981;63-B:319-27.

14. Levine AM, Edwards CC. The management of traumatic spondylolisthesis of the axis. J Bone Joint Surg Am. 1985;67:217-26.

15. Pellei DD. The fat C2 sign. Radiology. 2000;217:359-60.

16. Vaccaro AR, Hulbert RJ, Patel AA, et al. The subaxial cervical spine injury classification system: a novel approach to recognize the importance of morphology, neurology, and integrity of the disco-ligamentous complex. Spine. 2007;32:2365-74.

17. Patel AA, Dailey A, Brodke DS, Daubs M, Anderson PA, Hurlbert RJ, Vacccaro AR, Spine Trauma Study Group. Subaxial cervical spine trauma classification: the subaxial injury classification system and case examples. Neurosurg Focus. 2008;25:E8.

18. Splendiani A, Bruno F, Patriarca L, Barile A, Di Cesare E, Masciocchi C, Gallucci M. Thoracic spine trauma: advanced imaging modality. Radiol Med (Torino). 2016;121:780-92.

19. Palazzo C, Sailhan F, Revel M. Scheuermann's disease: an update. Joint Bone Spine. 2014;81:209-14.

20. Magerl F, Aebi M, Gertzbein SD, Harms J, Nazarian S. A comprehensive classification of thoracic and lumbar injuries. Eur Spine J. 1994;3:184-201.

21. Gerdhem P. Osteoporosis and fragility fractures: vertebral fractures. Best Pract Res Clin Rheumatol. 2013;27:743-55.

22. Mauch JT, Carr CM, Cloft H, Diehn FE. Review of the imaging features of benign osteoporotic and malignant vertebral compression fractures. AJNR Am J Neuroradiol. 2018;39:1584-92.

23. Geith T, Schmidt G, Biffar A, Dietrich O, Duerr HR, Reiser M, Baur-Melnyk A. Quantitative evaluation of benign and malignant vertebral fractures with diffusion-weighted MRI: what is the optimum combination of $b$ values for ADC-based lesion differentiation with the single-shot turbo spin-echo sequence? AJR Am J Roentgenol. 2014;203:582-8.

24. Denis F. The three column spine and its significance in the classification of acute thoracolumbar spinal injuries. Spine. 1983;8:817-31.

25. Khurana B, Sheehan SE, Sodickson A, Bono CM, Harris MB. Traumatic thoracolumbar spine injuries: what the spine surgeon wants to know. Radiogr Rev Publ Radiol Soc N Am Inc. 2013;33:2031-46.

26. Raniga SB, Skalski MR, Kirwadi A, Menon VK, Al-Azri FH, Butt $\mathrm{S}$. Thoracolumbar spine injury at CT: trauma/emergency radiology. Radiogr Rev Publ Radiol Soc N Am Inc. 2016;36:2234-5.

27. Bernstein MP, Mirvis SE, Shanmuganathan K. Chance-type fractures of the thoracolumbar spine: imaging analysis in 53 patients. AJR Am J Roentgenol. 2006;187:859-68.

28. Balling H, Weckbach A. Hyperextension injuries of the thoracolumbar spine in diffuse idiopathic skeletal hyperostosis. Spine. 2015;40:E61-7.

29. Syrmou E, Tsitsopoulos PP, Marinopoulos D, Tsonidis C, Anagnostopoulos I, Tsitsopoulos PD. Spondylolysis: a review and reappraisal. Hippokratia. 2010;14:17-21.

30. Standaert CJ, Herring SA. Spondylolysis: a critical review. Br J Sports Med. 2000;34:415-22.

31. Hu SS, Tribus CB, Diab M, Ghanayem AJ. Spondylolisthesis and spondylolysis. Instr Course Lect 57:431-445. JBJS. 2008;90:656-71. 
32. McTimoney CAM, Micheli LJ. Current evaluation and management of spondylolysis and spondylolisthesis. Curr Sports Med Rep. 2003;2:41-6.

33. Scavone JG, Latshaw RF, Weidner WA. Anteroposterior and lateral radiographs: an adequate lumbar spine examination. AJR Am J Roentgenol. 1981;136:715-7.

34. Kershen LM, Nacey NC, Patrie JT, Fox MG. Accuracy and efficacy of fluoroscopy-guided pars interarticularis injections on immediate and short-term pain relief. Skelet Radiol. 2016;45:1329-35.
35. Dvorak MF, Fisher CG, Fehlings MG, Rampersaud YR, Oner FC, Aarabi B, Vaccaro AR. The surgical approach to subaxial cervical spine injuries: an evidence-based algorithm based on the SLIC classification system. Spine. 2007;32:2620-9.

Open Access This chapter is licensed under the terms of the Creative Commons Attribution 4.0 International License (http://creativecommons. org/licenses/by/4.0/), which permits use, sharing, adaptation, distribution and reproduction in any medium or format, as long as you give appropriate credit to the original author(s) and the source, provide a link to the Creative Commons license and indicate if changes were made.

The images or other third party material in this chapter are included in the chapter's Creative Commons license, unless indicated otherwise in a credit line to the material. If material is not included in the chapter's Creative Commons license and your intended use is not permitted by statutory regulation or exceeds the permitted use, you will need to obtain permission directly from the copyright holder. 